\title{
Series editor preface
}

The decarbonization of the energy system is critical to reach the European climate objectives for both 2030 and 2050. In this respect, the "European Green Deal" put forward the need to ensure a smart integration of renewable energy sources, energy efficiency, and other sustainable solutions such as carbon capture. The "European Green Deal" also recognized the production of hydrogen, hydrogen storage, hydrogen networks, and the utilization of hydrogen as one of the important technology options that can ensure that the EU industry remains at the technology forefront and delivers breakthrough technologies in key industrial sectors.

The book provides compiling reviews on these aspects from internationally recognized researchers, industrialists, and government agencies, and assembles topclass contributions. The topical scope of the book is broad, ranging from hydrogen production, storage of hydrogen, and the multiple applications but also the development of many new materials and new technologies and innovations will be necessarily developed in many fields of physics, chemistry, biology, and mechanical engineering. Common to all the books in the series is that they represent top-notch research and are highly application-oriented, innovative, and relevant for industry.

The titles of the volumes in the series Hydrogen Technologies for Sustainable Economy are:

- Hydrogen Production and Energy Transition

- Hydrogen Storage for Sustainability

- Utilization of Hydrogen for Sustainable Energy and Fuels

They fall in the topics of energy, environment, and new materials but mobile applications such as automobiles, air, and space transport are becoming very popular.

The book series appeals to a wide range of readers with backgrounds in physics, chemistry, biology, and engineering but also for those interested in renewables energy, environment, economy, and industrial safety. Students at universities to scientists at institutes and technologists in industrial companies may also have a great interest in this new hydrogen energy source.

Ever since hydrogen was introduced many years ago it will greatly change our lives for the next generations. Developments are planned for many areas, which will result in a new "hydrogen economy"; in short, hydrogen technology is a hot topic!

Marcel Van de Voorde, November 2020 


\section{Hydrogen Technology - Innovations and Applications}

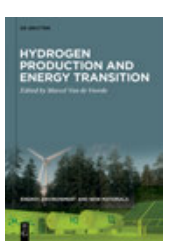

Volume 1

Hydrogen Production and Energy Transition

ISBN 978-3-11-059622-9

e-ISBN 978-3-11-059625-0

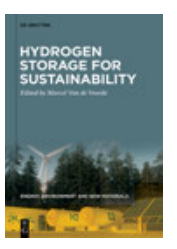

Volume 2

Hydrogen Storage for Sustainability

ISBN 978-3-11-059623-6

e-ISBN 978-3-11-059628-1

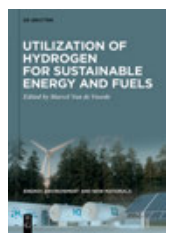

Volume 3

Utilization of Hydrogen for Sustainable Energy and Fuels

ISBN 978-3-11-059624-3

e-ISBN 978-3-11-059627-4 